\title{
Review of a novel disease entity, immunoglobulin G4-related disease
}

\author{
Takashi Maehara, Masafumi Moriyama, Seiji Nakamura \\ Section of Oral and Maxillofacial Oncology, Division of Maxillofacial Diagnostic and Surgical Sciences, \\ Faculty of Dental Science, Kyushu University, Fukuoka, Japan
}

\begin{abstract}
J Korean Assoc Oral Maxillofac Surg 2020;46:3-11)
Immunoglobulin G4 (IgG4)-related dacryoadenitis and sialoadenitis (IgG4-DS) are part of a multiorgan fibroinflammatory condition of unknown etiology termed IgG4-related disease (IgG4-RD), which has been recognized as a single diagnostic entity for less than 15 years. Histopathologic examination is critical for diagnosis of IgG4-RD. CD4+ T and B cells, including IgG4-expressing plasma cells, constitute the major inflammatory cell populations in IgG4-RD and are thought to cause organ damage and tissue fibrosis. Patients with IgG4-RD who have active, untreated disease exhibit significant increase of IgG4-secreting plasmablasts in the blood. Considerable insight into the immunologic mechanisms of IgG4-RD has been achieved in the last decade using novel molecular biology approaches, including next-generation and single-cell RNA sequencing. Exploring the interactions between CD4+ T cells and B lineage cells is critical for understanding the pathophysiology of IgG4-RD. Establishment of pathogenic T cell clones and identification of antigens specific to these clones constitutes the first steps in determining the pathogenesis of the disease. Herein, the clinical features and mechanistic insights regarding pathogenesis of IgG4-RD were reviewed.
\end{abstract}

Key words: Immunoglobulin G4-related disease, Immunoglobulin G4-related dacryoadenitis and sialoadenitis, Mikuliçz's disease, Küttner's tumor, T cell [paper submitted 2019. 12. 6 / accepted 2020. 1. 6]

\section{Introduction}

Immunoglobulin G4-related disease (IgG4-RD) is a novel clinical disease entity characterized by a chronic fibroinflammatory condition with lymphoplasmacytic infiltration in affected lesions ${ }^{1}$. The disease mimics many malignant, infectious, and inflammatory disorders with histologic features that are consistently observed across the organs involved. Human IgG can be classified into four subtypes, IgG1, IgG2, $\mathrm{IgG} 3$, and $\mathrm{IgG} 4$, of which $\mathrm{IgG} 4$ is the rarest. However, IgG4$\mathrm{RD}$ is characterized by elevated serum $\mathrm{IgG} 4$ concentration and tissue infiltrated by $\mathrm{IgG} 4+\mathrm{B}$ cells and is termed $\mathrm{IgG} 4$ class-switching disease ${ }^{1,2}$. IgG4-RD may be present in a certain proportion of patients across a wide variety of diseases

\section{Takashi Maehara}

Section of Oral and Maxillofacial Oncology, Division of Maxillofacial Diagnostic and Surgical Sciences, Faculty of Dental Science, Kyushu University, 3-1-1, Maidashi Higashi-ku, Fukuoka 812-8582, Japan

TEL: +81-92-642-6447 FAX: +81-92-642-6386

E-mail:tmaehara@dent.kyushu-u.ac.jp

ORCID: https://orcid.org/0000-0002-7877-2161

(c) This is an open-access article distributed under the terms of the Creative Commons Attribution Non-Commercial License (http://creativecommons.org/ licenses/by-nc/4.0/), which permits unrestricted non-commercial use, distribution, and reproduction in any medium, provided the original work is properly cited.

Copyright (C) 2020 The Korean Association of Oral and Maxillofacial Surgeons. All rights reserved. including Mikuliçz's disease (MD), Küttner's tumor (KT) ${ }^{3}$, Riedel's thyroiditis, kidney disease, autoimmune pancreatitis, hypophysitis, interstitial pneumonitis, interstitial nephritis, prostatitis, lymphadenopathy, retroperitoneal fibrosis, inflammatory aortic aneurysm, and inflammatory pseudotumor. Thus, this disease can occur in a variety of organs including the pancreas, kidney, lung, lymph nodes, bile duct, liver, aorta, prostate, retroperitoneum, thyroid, and major salivary glands ${ }^{1}$. The diagnosis of IgG4-RD relies heavily on histopathological analysis and correlation of histology findings with clinical, serological, and radiological data. International consensus statements have been published regarding the nomenclature, pathologic findings, and clinical management of IgG4-RD ${ }^{4,5}$. Recently, Wallace et al. ${ }^{6}$ identified four distinctive IgG4-RD phenotypes based on organ involvement and reported that being Asian or female may predispose individuals to disease limited to the head and neck, especially in the salivary and lacrimal glands. The American College of Rheumatology/European League Against Rheumatism Classification Criteria are currently being developed ${ }^{5}$. Herein, the clinical characteristics of IgG4-RD are described, and up-todate information on mechanistic insights using novel molecular biology approaches is provided. 


\section{Immunological Insights into the Pathogenesis}

\section{Imaging of $\lg G 4-R D$}

Computed tomography (CT), magnetic resonance imaging, and ultrasonography (US) are useful tools to assess organ involvement, monitor therapeutic responses, and guide interventional treatments for IgG4-RD. Furthermore, F-fluorodeoxyglucose (FDG) positron emission tomography/computed tomography $(\mathrm{PET} / \mathrm{CT})$ was used to characterize IgG4-RD and showed multi-organ involvement.(Fig. 1. A) FDG-PET/ $\mathrm{CT}$ enables acquisition of whole-body images and provides functional information regarding disease activity. For example, when focusing on an affected salivary mandibular gland of an IgG4-RD patient, a US image of a lesion showed a hypoechoic area with a reticular pattern in the superficial part and a hypoechoic area with a nodal pattern and high vascularity $^{7,8}$.(Fig. 1. B)

\section{Affected salivary glands}

Both major and minor salivary glands can be affected by IgG4-related dacryoadenitis and sialoadenitis (IgG4-DS).(Fig. 1. C) IgG4-DS is commonly encountered by oral surgeons in the context of MD or KT, especially in Asians, which comprises simultaneous bilateral and symmetrical enlargement of the lacrimal and salivary glands. Some patients, however, only exhibit lacrimal gland disease or may present with unilateral submandibular gland involvement. For many decades, MD was thought to represent a subtype of Sjögren's syndrome (SS); however, now these two diseases are known to be different ${ }^{9}$.

Comprehensive diagnostic criteria have been proposed for IgG4-RD. Furthermore, organ-specific criteria have been proposed for IgG4-DS ${ }^{9}$. Using these criteria, biopsies of affected lesions can be used to exclude diseases that often mimic IgG4-DS, including lymphoma, SS, sarcoidosis, sialodocholithiasis, granulomatosis with polyangiitis, and multicentric Castleman's disease ${ }^{10,11}$. An incisional or excisional biopsy of affected submandibular glands is often the best method for establishing a definitive diagnosis of IgG4-DS ${ }^{9,12}$.

\section{Genetic background of IgG4-RD patients}

In numerous previous studies, have investigated risk factors for IgG4-RD, especially type I autoimmune pancreatitis
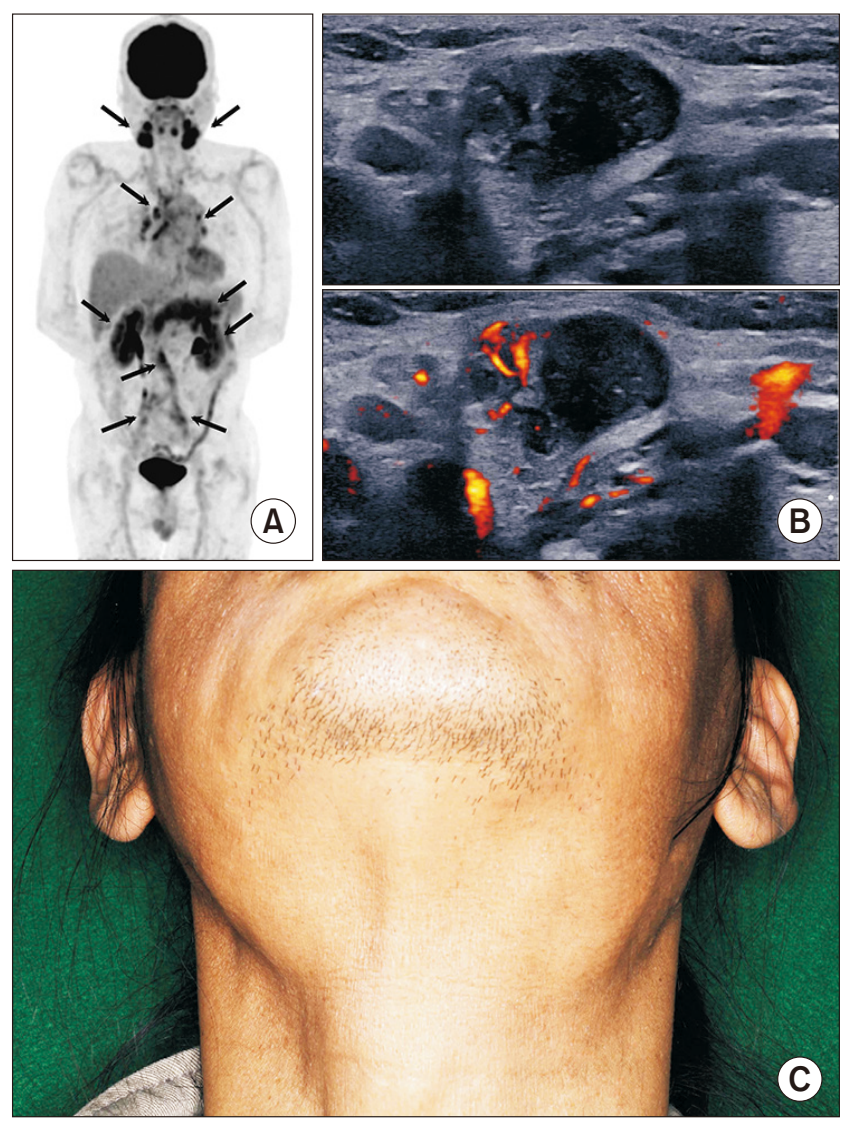

Fig. 1. Immunoglobulin G4-related disease (IgG4-RD) tends to form tumefactive lesions. A. A 60-year-old male with IgG4-RD showed multi-organ involvement. F-fluorodeoxyglucose (FDG)positron emission tomography/computed tomography (PET/CT) showed multiple intense uptakes in the bilateral lacrimal glands, submandibular glands, lymph nodes, kidney, pancreas, and retroperitoneum (arrows). B. Ultrasonography shows hypoechoic areas with a nodal pattern and hyperechoic lines (upper). In Doppler mode, the nodal area shows relatively high vascularization (lower). C. Bilateral enlargement of the submandibular glands in an IgG4$\mathrm{RD}$ patient.

Takashi Maehara et al: Review of a novel disease entity, immunoglobulin G4-related disease. J Korean Assoc Oral Maxillofac Surg 2020

(IgG4-related pancreatitis), were investigated. The $H L A$ $D R B 1 * 0405$ and $H L A-D Q B 1 * 0401$ haplotypes were frequently found in Japanese patients with IgG4-related pancreatitis $^{13}$. In addition to HLA risk loci described in previous reports, several non-human leukocyte antigen (HLA) genes have been identified as risk genes of IgG4-RD. Terao et al. ${ }^{14}$ reported that, because HLA loci usually showed stronger associations with autoimmune diseases compared with nonHLA loci, detailed analyses of the HLA regions with finemapping genome-wide association study (GWAS) signals using next-generation sequencing and prioritizing amino acid variants or positions critical for IgG4-RD should be conducted as sub-analyses of GWAS. 


\section{Histopathology of IgG4-RD}

Histopathology is critical for diagnosis of IgG4-RD. Major central pathology features include lymphocytic infiltration, obliterate phlebitis, and storiform fibrosis in the affected lesions.(Fig. 2. A) IgG4+ B cells and CD4+ and CD8+ T cells are commonly present (Fig. 2. B-D), and most IgG in the affected organs is IgG4.(Fig. 2. F, 2. G) The finding of abundant IgG4+ plasma cells is helpful to differentiate IgG4-RD from other mimic disorders with a similar presentation. However, IgG4-RD cannot be diagnosed based only on IgG4+ cell infiltration because these plasma cells are present in many other inflammatory disorders ${ }^{15}$.

IgG4 is generally considered a non-inflammatory immunoglobulin due to its limited ability to fix complement and bind activating Fc receptors ${ }^{16}$. Notably, there is no evidence that IgG4 has a primary role in the pathophysiology of IgG4-RD. Furthermore, the activity of IgG4-RD does not always correlate well with serum $\operatorname{IgG} 4$ concentration ${ }^{17}$.

\section{Role of T-B interactions in IgG4-RD}

It is important to determine which cells are crucial for pathogenesis of IgG4-RD. The first reliable report on the pathophysiology of this disease was from preliminary studies of rituximab (RTX) therapy (anti-CD20 B cell depletion therapy) showing that $\mathrm{B}$ cell depletion induced disease remission and led to clinical improvement ${ }^{18-20}$. Active and untreated IgG4-RD patients have an oligoclonally expanded population of circulating plasmablasts with a restricted oligoclonal $\mathrm{B}$ cell receptor repertoire ${ }^{21}$, strongly indicating that IgG4-RD is an antigen-driven disease ${ }^{22}$. Clonally expanded plasmablasts from IgG4-RD blood are a hallmark of active IgG4-RD. In flow cytometry studies after RTX therapy, clinical improvement correlated with selective depletion of this B cell subpopulation. Oligoclonal proliferation of antibody-producing cells was correlated with disease activity, and marked clinical responsiveness to $\mathrm{B}$ cell depletion indicated the importance of $B$ cells in the pathophysiology of IgG4-RD ${ }^{21,23,24}$.

$\mathrm{T}$ cells are also implicated in the pathogenesis of IgG4$\mathrm{RD}$ for several reasons, the most obvious is the histological observation that many CD4 $+\mathrm{T}$ cells are present in affected tissues $^{4}$.(Fig. 2. C) In addition, IgG4-RD was linked to HLA class II based on a GWAS of a Japanese population. T cell responses have long been considered central to the pathophysiology of IgG4-RD; however, interest regarding the $\mathrm{T}$
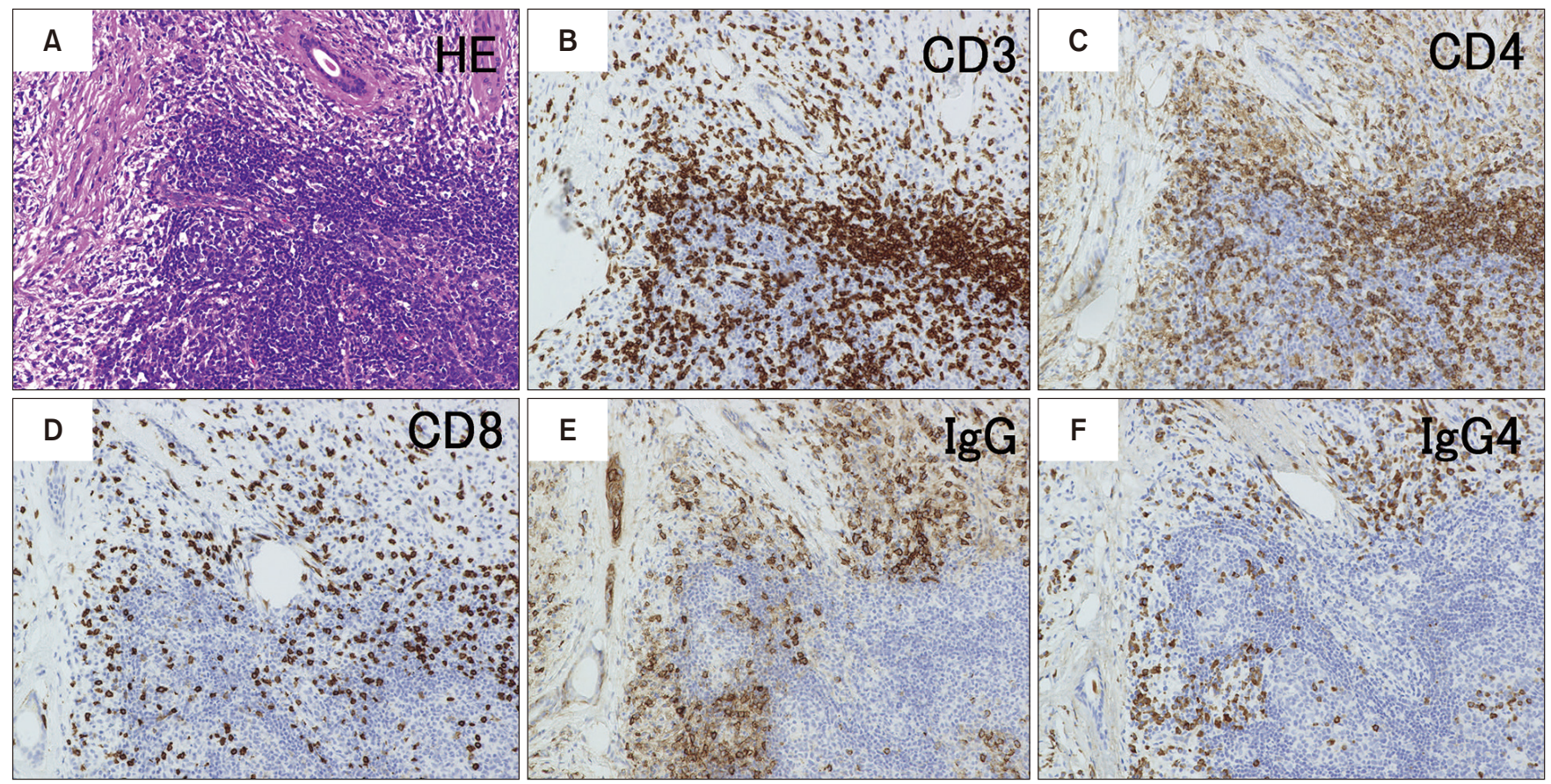

Fig. 2. Histopathological features of a submandibular gland affected by fibro-inflammation in an immunoglobulin G4-related dacryoadenitis and sialoadeniti (IgG4-DS) patient. The inflammatory cell infiltrate mainly consists of lymphocytes and plasma cells, and fibrosis is evident throughout the tissue. A. Staining with H\&E $(\times 200)$ shows dense fibrosis with lymphocytes, plasma cells, and occasional eosinophils embedded within. B-D. Immunostaining for CD3 (×200), CD4 (×200), and CD8 (×200) shows that T cells are diffusely distributed. E, F. Immunostaining for IgG (×200) and IgG4 (×200) shows that most lgG-positive cells in affected tissues are also lgG4-positive.

Takashi Maehara et al: Review of a novel disease entity, immunoglobulin G4-related disease. JKorean Assoc Oral Maxillofac Surg 2020 
cell population has recently shifted. IgG4-RD has long been considered a CD4+ type 2 helper $\mathrm{T}(\mathrm{Th} 2) / \mathrm{CD} 4+$ regulatory helper $\mathrm{T}$ (Treg)-driven condition. The presence of dense fibrotic tissues and abundant IgG4+ plasma cells is consistent with an underlying "modified Th2 immune reaction," which is associated with production of both Th2 (interleukin [IL]-4 and IL-13) and Treg-related cytokines (transforming growth factor [TGF]- $\beta 1$ and IL-10) ${ }^{25}$. A novel population of effector memory CD4+ T cells with a cytotoxic function (CD4+ CTLs) was described in IgG4-RD patients using nextgeneration sequencing ${ }^{20,26}$. CD4+ CTLs might be antigenexperienced $\mathrm{T}$ cells with features of both CD4+ and CD8+ T lymphocytes, which retain the ability to kill target cells in an major histocompatibility complex (MHC) class II-restricted manner $^{27}$. This cell population likely arises from chronic antigenic stimulation. Notably, a significant reduction of circulating CD4+ CTLs and circulating plasmablasts was observed following RTX therapy ${ }^{20,28}$ or glucocorticoid therapy in IgG4$\mathrm{RD}^{29}$. In contrast, circulating naïve CD4+ T cells remained stable after treatment interventions ${ }^{20,28}$, indicating that this cell population has an important role in the pathophysiology of IgG4-RD.

Pillai et al. ${ }^{30}$ showed that B cell depletion therapy was effective in autoimmune diseases with somatically hypermutated B cells or plasmablasts at disease sites, which likely serve as critical antigen-presenting cells for a subset of diseasecausing $\mathrm{T}$ cells. Taken together, these findings strongly indicate an antigen-driven process that requires a critical interaction between CD4+ CTLs and activated B cells ${ }^{31}$. Regarding pathophysiology, dominantly expanded B cells possibly maintain or present antigens to a subset of expanded CD4+ CTLs in affected tissue sites of IgG4-RD patients ${ }^{31}$.

A clonally expanded activated B cell population and multiple subsets of T cells are hallmarks of IgG4-RD. New molecular biological technologies have increased the understanding of the pathogenesis of this disease related to activation-causing B cells and CD4+ CTLs. Currently, the focus of research is shifting to follicular helper T (Tfh) cells. Generally, Tfh cells help B cells during T-dependent immune responses. Tfh cells are essential for germinal center formation and affinity maturation, as well as development of most high-affinity antibodies and memory B cells, indicating that disease-specific Tfh cells promote specific class switching to $\mathrm{IgG} 4^{32}$. Recently, an increased number of blood memory type 2 Tfh (Tfh2) cells has been noted in patients with IgG4$\mathrm{RD}^{33-35}$. Especially, Akiyama et al. ${ }^{34}$ reported that circulating Tfh2 (cTfh2) cells, but not cTfh1 or cTfh17 cells, induced differentiation of naïve B cells into CD19+ plasmablasts and enhanced production of IgG4 in patients with IgG4-RD. Tfh cells in germinal centers cooperate with B cells in production of antibodies. However, there is no evidence connecting subsets of Tfh cells in the blood with functional counterparts in secondary or tertiary lymphoid organs.

\section{Autoantibodies in IgG4-RD}

Four different autoantigens have been described as potential triggers for IgG4-RD: prohibitin, annexin A11, laminin 511, and galectin- $3^{36-38}$. Shiokawa et al. ${ }^{38}$ reported antilaminin 511 in $51 \%$ of Japanese IgG4-RD patients. However, Liu et al. ${ }^{39}$ recently reported anti-laminin 511 in only $7 \%$ of Caucasian IgG4-RD patients. They reported that the higher prevalence of HLA class II molecules suggests that East Asians compared with Caucasians might be more efficient at presenting immune-dominant peptides from laminin 511 to activated CD4+ T cells, thereby permitting $\mathrm{IgG}$ or $\mathrm{IgG} 4$ antibody responses. This highlights the importance of crossvalidation studies in patients of both East Asian and Western descent $^{39}$.

\section{Innate immunity in lgG4-RD}

Innate immunity was also recently shown to have a role in initiation of IgG4-RD. Macrophages, especially CD68+ CD163+ alternatively activated (M2) macrophages, were abundant in affected IgG4-RD tissues and expressed profibrotic factors (CCL18 and TGF- $\beta)^{40-42}$. Furthermore, in several studies, B cell activating factor (BAFF) secreted by macrophages and basophils reportedly induced IgG4 production by B cells via activation of Toll-like receptors (TLR) ${ }^{43,44}$. Thus, activated TLR signaling might promote IgG4 production in this disease. Although IgG4-RD model mice have not been established, we recently reported that human TLR7 transgenic (huTlr7) Tg mice developed fibrosis and lymphocytic infiltration in the salivary mandibular glands (SMGs), pancreas, and lung ${ }^{45}$. A more thorough understanding of how macrophages contribute to IgG4-RD might help elucidate the mechanism of fibrosis in this disease. However, additional research is required to establish a mouse model of IgG4-RD.

\section{Targeted treatment results}

Most clinical manifestations of IgG4-RD respond to glucocorticoids, which are the first-line, standard care approach 
for most patients ${ }^{1,46}$. Masaki et al ${ }^{47}$ reported a multicenter phase II prospective clinical trial of glucocorticoid therapy in Japanese patients with IgG4-RD. Hong et al. ${ }^{48}$ reported that glucocorticoid therapy was beneficial for induction and maintenance therapy in Chinese patients with IgG4-DS. In a randomized, controlled trial of long-term maintenance corticosteroid therapy, Masamune et al. ${ }^{49}$ reported that maintenance glucocorticoid therapy was effective in reducing relapse in Japanese patients with IgG4-related pancreatitis. One conventional treatment included an initial prednisolone dose of 0.6 to $1.0 \mathrm{mg} / \mathrm{kg}$ daily; after 2 to 4 weeks, the dose was tapered by $5 \mathrm{mg}$ every 1 to 2 weeks based on clinical response $^{50}$. Clinical improvement after initiation of glucocorticoid therapy is rapid, and a follow-up serological evaluation should be performed approximately 2 weeks after therapy. PET/CT may be useful for assessment of treatment responses. A poor response to glucocorticoid therapy might be indicative of other diagnoses, particularly cancer. Furthermore, response to glucocorticoids varies with respect to affected organs and degree of fibrosis. After therapy, salivary secretion in patients with IgG4-DS is more likely to be improved, contrary to glandular function in $\mathrm{SS}^{51}$. These clinical conditions consistent with histologically ductal epithelial cell apoptosis are characteristic of SS but not IgG4-DS.

RTX therapy is typically used for patients who do not respond to glucocorticoids or who experience disease flares during or after glucocorticoid tapers. Important mechanistic insights correlating with pathogenesis of IgG4-RD have been reported after B cell depletion ${ }^{18-21,31}$.

\section{Conclusion}

Fig. 3 shows immunological responses in IgG4-RD subjects who harbor plasmablasts or other activated B cells specific for a subset of autoantigens, including galectin-3, which exhibit oligoclonal restriction resulting in clonal expansion of CD4+ CTLs in tissues. The B lineage cells might also present antigens to relevant Tfh cells ${ }^{52}$. Furthermore, in IgG4-RD, IL4-secreting Tfh cells are increased in blood and tissues, which might enable a subset of B cells to undergo differentiation and somatic mutation. In recent studies, interactions among clonally expanded CD4+ CTLs, Tfh cells and B cells were criti-
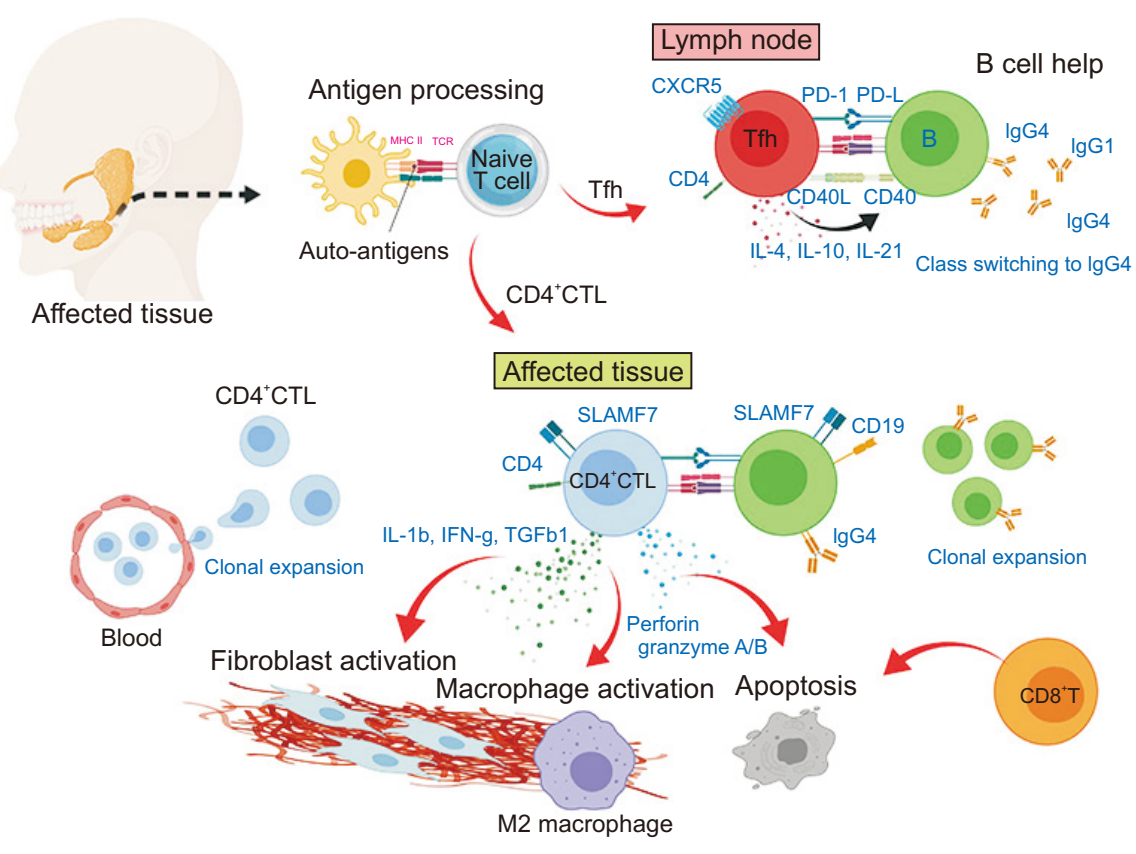

Fig. 3. Immunological responses in immunoglobulin G4-related disease (IgG4-RD). Chronic stimulation via activated antigen-presenting cells induces differentiation of naïve T cells into CD4+ CTLs and follicular helper T (Tfh) cells. In secondary lymphoid organs, Tfh cells collaborate with B cells to drive lgG4 class switching, somatic hypermutation, and plasmablast differentiation of antigen-detecting B cells. Clonally expanded CD4+ CTLs and activated B cells, including lgG4 secreting plasmablasts, might cause lgG4-RD. Reactivation of CD4+ CTLs may require presentation of antigens, including galectin-3, by plasmablasts or other activated B cells at affected tissue sites. Activated CD4+ CTLs and CD8+ cytotoxic T cells may mediate fibrosis and inflammation associated with cytokine secretion or induction of cell death. Activated macrophages may contribute to fibrosis associated with pro-fibrotic cytokine expression.

Takashi Maehara et al: Review of a novel disease entity, immunoglobulin G4-related disease. J Korean Assoc Oral Maxillofac Surg 2020 
Table 1. Principal findings regarding the pathogenesis of lgG4-RD

\begin{tabular}{|c|c|}
\hline Involvement in the pathogenesis of IgG4-RD & Reference No. \\
\hline \multicolumn{2}{|l|}{ Organs and conditions associated with IgG4-RD } \\
\hline Orbit & 53 \\
\hline Salivary glands (Mikuliçz's disease, Küttner's tumor) & $9,51,54,55$ \\
\hline Ears, nose, throat, and maxillary mass & 56 \\
\hline Thyroid gland (Riedel's thyroiditis) & 57 \\
\hline Lymph nodes (lymphadenopathy) & 58 \\
\hline Aorta & 59 \\
\hline Retroperitoneum (idiopathic retroperitoneal fibrosis, Ormond's disease) & 60 \\
\hline Lungs & 61 \\
\hline Kidneys & 62 \\
\hline Pancreas (type II autoimmune pancreatitis) & 63 \\
\hline IgG4-related sclerosing cholangitis & 64 \\
\hline \multicolumn{2}{|l|}{ B cell phenotype in IgG4-RD } \\
\hline Oligoclonally expanded IgG4-secreting plasmablasts & 21 \\
\hline Plasmablasts as a biomarker for IgG4-RD & 28 \\
\hline Clinical improvement correlated with B cell depletion therapy & $20,24,28$ \\
\hline \multicolumn{2}{|l|}{ T cell phenotype in IgG4-RD } \\
\hline Th2 responses may result from concomitant atopic manifestations & 65 \\
\hline IL-33 might contribute to pathogenesis via aberrant activation of Th2 immune responses & 42 \\
\hline Th2 and Treg cells are important for IgG4 production in IgG4-DS & 25 \\
\hline $\begin{array}{l}\text { Overexpression of IL-21 promotes tertiary lymphoid organ formation and IgG4 production in salivary glands of } \\
\text { IgG4-DS patients }\end{array}$ & 66 \\
\hline Clonally expanded CD4+ CTL in IgG4-RD is decreased following rituximab treatment & 20 \\
\hline CD4+ CTLs are increased in IgG4-RD and decreased following glucocorticoid treatment & 29 \\
\hline Clonally expanded CD4+ CTL and pathogenesis of IgG4-RD; review & 19 \\
\hline Circulating IgG4+ plasmablasts are oligoclonally expanded in active and relapsing IgG4-RD & 21 \\
\hline Plasmablasts as a biomarker for IgG4-RD independent of serum IgG4 level & 28 \\
\hline Increased IL-4-secreting Tfh cells are associated with IgG4 class switching in vivo & 52 \\
\hline $\begin{array}{l}\text { Increased circulating Tfh } 2 \text { cells and their capacity to help naïve B cells differentiate into plasmablasts and IgG4 } \\
\text { production in vitro }\end{array}$ & 33,34 \\
\hline Tfh cells in the pathogenesis of IgG4-RD; review & 67 \\
\hline Lesional Tfh cells in the pathogenesis of IgG4-RD & 68 \\
\hline Peripheral helper T cells in IgG4-RD & 69 \\
\hline \multicolumn{2}{|l|}{ Principal findings regarding autoantigens in IgG4-RD } \\
\hline Identification of galectin-3 as an autoantigen in IgG4-RD & 70 \\
\hline Pathogenicity of IgG1 and IgG4 in IgG4-related pancreatitis & 71 \\
\hline Laminin 511 is a target antigen in IgG4-related pancreatitis & 38 \\
\hline Specific antigen in IgG4-RD; review & 22 \\
\hline Annexin A11 is targeted by IgG4 and IgG1 autoantibodies in IgG4-RD & 37 \\
\hline Prohibitin is involved in IgG4-RD & 36 \\
\hline Disease severity is associated with increased autoantibody diversity in IgG4-RD & 39 \\
\hline \multicolumn{2}{|l|}{ Macrophages in IgG4-RD } \\
\hline CD68+CD163+ type 2 macrophages contribute to fibrosis in IgG4-RD & 72 \\
\hline MARCO expressing type 2 macrophages in IgG4-RD & 73 \\
\hline TLR7 expressing type 2 macrophages may promote activation of Th2 immune responses via IL- 33 secretion & 45 \\
\hline \multicolumn{2}{|l|}{ Useful IgG4-RD reviews } \\
\hline IgG4-related disease & 1 \\
\hline Treatment of IgG4-RD: current and future approaches & 74 \\
\hline Immunological mechanism in IgG4-RD & 19 \\
\hline Emerging treatment models in rheumatology & 75 \\
\hline Clinical features and mechanistic insights regarding IgG4-DS & 9 \\
\hline
\end{tabular}

(IgG4-RD: immunoglobulin G4-related disease, Th2: type 2 helper T, IL: interleukin, IgG4-DS: immunoglobulin G4-related dacryoadenitis and sialoadenitis, Tfh: follicular helper T, MARCO: macrophage receptor with collagenous structure, TLR: Toll-like receptor)

Takashi Maehara et al: Review of a novel disease entity, immunoglobulin G4-related disease. J Korean Assoc Oral Maxillofac Surg 2020

cal for pathogenesis of IgG4-RD. M2 macrophages are the dominant population in affected tissues and might contribute to fibrosis through production of pro-fibrotic cytokines. The important of several findings for the pathogenesis of IgG4RD has been reported in Table $1^{19-22,24,25,28,29,33,34,36-39,42,45,51-75}$.

\section{ORCID}

Takashi Maehara, https://orcid.org/0000-0002-7877-2161 Masafumi Moriyama, https://orcid.org/0000-0003-2911-2244 Seiji Nakamura, https://orcid.org/0000-0002-6373-8817 


\section{Authors' Contributions}

T.M. participated in conceptualization, investigation, and writing - original draft, review, and editing. M.M. and S.N. participated in review and editing. All authors read and approved the final manuscript.

\section{Acknowledgements}

This study was supported by JSPS KAKENHI Grant Numbers $19 \mathrm{H} 03854$ and $18 \mathrm{KK} 0260$ and by the "Takeda Science Foundation" to T.M. We thank the Edanz Group (www.edanzediting.com/ac) for editing a draft of this manuscript.

\section{Ethics Approval and Consent to Participate}

The study design and methods were approved by the Institutional Review Board of the Center for Clinical and Translational Research of Kyushu University Hospital (IRB Nos. 25287 and 26-86) and followed the tenets of the Declaration of Helsinki. Informed consent was obtained from all patients.

\section{Conflict of Interest}

No potential conflict of interest relevant to this article was reported.

\section{References}

1. Kamisawa T, Zen Y, Pillai S, Stone JH. IgG4-related disease. Lancet 2015;385:1460-71.

2. Mahajan VS, Mattoo H, Deshpande V, Pillai SS, Stone JH. IgG4related disease. Annu Rev Pathol 2014;9:315-47.

3. Furukawa S, Moriyama M, Kawano S, Tanaka A, Maehara T, Hayashida JN, et al. Clinical relevance of Küttner tumour and IgG4-related dacryoadenitis and sialoadenitis. Oral Dis 2015;21:257-62.

4. Deshpande V, Zen Y, Chan JK, Yi EE, Sato Y, Yoshino T, et al. Consensus statement on the pathology of IgG4-related disease. Mod Pathol 2012;25:1181-92.

5. Khosroshahi A, Wallace ZS, Crowe JL, Akamizu T, Azumi A, Carruthers $\mathrm{MN}$, et al. International consensus guidance statement on the management and treatment of IgG4-related disease. Arthritis Rheumatol 2015;67:1688-99.

6. Wallace ZS, Zhang Y, Perugino CA, Naden R, Choi HK, Stone JH. Clinical phenotypes of IgG4-related disease: an analysis of two international cross-sectional cohorts. Ann Rheum Dis 2019;78:40612.

7. Shimizu M, Okamura K, Kise Y, Takeshita Y, Furuhashi H, Weerawanich W, et al. Effectiveness of imaging modalities for screening IgG4-related dacryoadenitis and sialadenitis (Mikulicz's disease) and for differentiating it from Sjögren's syndrome (SS), with an emphasis on sonography. Arthritis Res Ther 2015;17:223.

8. Sakamoto M, Moriyama M, Shimizu M, Chinju A, Mochizuki
K, Munemura R, et al. The diagnostic utility of submandibular gland sonography and labial salivary gland biopsy in IgG4-related dacryoadenitis and sialadenitis: Its potential application to the diagnostic criteria. Mod Rheumatol 2019. doi: 10.1080/14397595.2019.1576271. [Epub ahead of print]

9. Maehara T, Pillai S, Stone JH, Nakamura S. Clinical features and mechanistic insights regarding IgG4-related dacryoadenitis and sialoadenitis: a review. Int J Oral Maxillofac Surg 2019;48:908-16.

10. Umehara H, Okazaki K, Nakamura T, Satoh-Nakamura T, Nakajima A, Kawano M, et al. Current approach to the diagnosis of IgG4-related disease - combination of comprehensive diagnostic and organ-specific criteria. Mod Rheumatol 2017;27:381-91.

11. Li W, Chen Y, Sun ZP, Cai ZG, Li TT, Zhang L, et al. Clinicopathological characteristics of immunoglobulin G4-related sialadenitis. Arthritis Res Ther 2015;17:186.

12. Moriyama M, Furukawa S, Kawano S, Goto Y, Kiyoshima T, Tanaka A, et al. The diagnostic utility of biopsies from the submandibular and labial salivary glands in IgG4-related dacryoadenitis and sialoadenitis, so-called Mikulicz's disease. Int J Oral Maxillofac Surg 2014;43:1276-81.

13. Kawa S, Ota M, Yoshizawa K, Horiuchi A, Hamano H, Ochi Y, et al. HLA DRB10405-DQB10401 haplotype is associated with autoimmune pancreatitis in the Japanese population. Gastroenterology 2002;122:1264-9.

14. Terao C, Ota M, Iwasaki T, Shiokawa M, Kawaguchi S, Kuriyama $\mathrm{K}$, et al. IgG4-related disease in the Japanese population: a genome-wide association study. Lancet Rheumatol 2019;1:PE1422.

15. Strehl JD, Hartmann A, Agaimy A. Numerous IgG4-positive plasma cells are ubiquitous in diverse localised non-specific chronic inflammatory conditions and need to be distinguished from IgG4related systemic disorders. J Clin Pathol 2011;64:237-43.

16. Bruhns P, Iannascoli B, England P, Mancardi DA, Fernandez N, Jorieux S, et al. Specificity and affinity of human Fcgamma receptors and their polymorphic variants for human $\mathrm{IgG}$ subclasses. Blood 2009;113:3716-25.

17. Carruthers MN, Khosroshahi A, Augustin T, Deshpande V, Stone $\mathrm{JH}$. The diagnostic utility of serum IgG4 concentrations in IgG4related disease. Ann Rheum Dis 2015;74:14-8.

18. Maehara T. [IgG4-related disease -mechanistic insights from both clinical and immunologic understanding of this condition]. Nihon Rinsho Meneki Gakkai Kaishi 2017;40:206-12. Japanese.

19. Mattoo H, Stone JH, Pillai S. Clonally expanded cytotoxic $\mathrm{CD}^{+} \mathrm{T}$ cells and the pathogenesis of IgG4-related disease. Autoimmunity 2017;50:19-24.

20. Mattoo H, Mahajan VS, Maehara T, Deshpande V, Della-Torre E, Wallace ZS, et al. Clonal expansion of CD4(+) cytotoxic T lymphocytes in patients with IgG4-related disease. J Allergy Clin Immunol 2016;138:825-38.

21. Mattoo H, Mahajan VS, Della-Torre E, Sekigami Y, Carruthers M, Wallace ZS, et al. De novo oligoclonal expansions of circulating plasmablasts in active and relapsing IgG4-related disease. J Allergy Clin Immunol 2014;134:679-87.

22. Haldar D, Hirschfield GM. Deciphering the biology of IgG4related disease: specific antigens and disease? Gut 2018;67:602-5.

23. Carruthers MN, Topazian MD, Khosroshahi A, Witzig TE, Wallace ZS, Hart PA, et al. Rituximab for IgG4-related disease: a prospective, open-label trial. Ann Rheum Dis 2015;74:1171-7.

24. Della-Torre E, Feeney E, Deshpande V, Mattoo H, Mahajan V, Kulikova M, et al. B-cell depletion attenuates serological biomarkers of fibrosis and myofibroblast activation in IgG4-related disease. Ann Rheum Dis 2015;74:2236-43.

25. Tanaka A, Moriyama M, Nakashima H, Miyake K, Hayashida JN, Maehara T, et al. Th2 and regulatory immune reactions contribute to IgG4 production and the initiation of Mikulicz disease. Arthritis Rheum 2012;64:254-63.

26. Maehara T, Mattoo H, Ohta M, Mahajan VS, Moriyama M, Yam- 
auchi $\mathrm{M}$, et al. Lesional CD4+ IFN- $\gamma+$ cytotoxic T lymphocytes in IgG4-related dacryoadenitis and sialoadenitis. Ann Rheum Dis 2017;76:377-85.

27. Tian Y, Sette A, Weiskopf D. Cytotoxic CD4 T cells: differentiation, function, and application to dengue virus infection. Front Immunol 2016;7:531.

28. Wallace ZS, Mattoo H, Carruthers M, Mahajan VS, Della Torre $\mathrm{E}$, Lee $\mathrm{H}$, et al. Plasmablasts as a biomarker for IgG4-related disease, independent of serum IgG4 concentrations. Ann Rheum Dis 2015;74:190-5.

29. Della-Torre E, Bozzalla-Cassione E, Sciorati C, Ruggiero E, Lanzillotta M, Bonfiglio S, et al. A CD8 $\alpha$ - subset of CD4+SLAMF7+ cytotoxic $\mathrm{T}$ cells is expanded in patients with IgG4-related disease and decreases following glucocorticoid treatment. Arthritis Rheumatol 2018;70:1133-43.

30. Pillai S, Mattoo H, Cariappa A. B cells and autoimmunity. Curr Opin Immunol 2011;23:721-31.

31. Maehara T, Moriyama M, Nakamura S. Pathogenesis of IgG4related disease: a critical review. Odontology 2019;107:127-32.

32. Crotty S. Follicular helper CD4 T cells (TFH). Annu Rev Immunol 2011;29:621-63.

33. Akiyama M, Suzuki K, Yamaoka K, Yasuoka H, Takeshita M, Kaneko Y, et al. Number of circulating follicular helper $2 \mathrm{~T}$ cells correlates with IgG4 and interleukin-4 levels and plasmablast numbers in IgG4-related disease. Arthritis Rheumatol 2015;67:2476-81.

34. Akiyama M, Yasuoka H, Yamaoka K, Suzuki K, Kaneko Y, Kondo $\mathrm{H}$, et al. Enhanced IgG4 production by follicular helper $2 \mathrm{~T}$ cells and the involvement of follicular helper $1 \mathrm{~T}$ cells in the pathogenesis of IgG4-related disease. Arthritis Res Ther 2016;18:167.

35. Grados A, Ebbo M, Piperoglou C, Groh M, Regent A, Samson M, et al. T cell polarization toward TH2/TFH2 and TH17/TFH17 in patients with IgG4-related disease. Front Immunol 2017;8:235.

36. Du H, Shi L, Chen P, Yang W, Xun Y, Yang C, et al. Prohibitin is involved in patients with IgG4 related disease. PLoS One 2015;10:e0125331.

37. Hubers LM, Vos H, Schuurman AR, Erken R, Oude Elferink RP, Burgering B, et al. Annexin A11 is targeted by IgG4 and IgG1 autoantibodies in IgG4-related disease. Gut 2018;67:728-35.

38. Shiokawa M, Kodama Y, Sekiguchi K, Kuwada T, Tomono T, Kuriyama K, et al. Laminin 511 is a target antigen in autoimmune pancreatitis. Sci Transl Med 2018;10:eaaq0997.

39. Liu H, Perugino CA, Ghebremichael M, Wallace ZS, Montesi SB, Stone $\mathrm{JH}$, et al. Disease severity is linked to an increase in autoantibody diversity in IgG4-related disease. Arthritis Rheumatol 2019. doi: 10.1002/art.41140. [Epub ahead of print]

40. Tsuboi H, Nakai Y, Iizuka M, Asashima H, Hagiya C, Tsuzuki S, et al. DNA microarray analysis of labial salivary glands in IgG4related disease: comparison with Sjögren's syndrome. Arthritis Rheumatol 2014;66:2892-9.

41. Tsuboi H, Matsuo N, Iizuka M, Tsuzuki S, Kondo Y, Tanaka A, et al. Analysis of IgG4 class switch-related molecules in IgG4-related disease. Arthritis Res Ther 2012;14:R171.

42. Furukawa S, Moriyama M, Miyake K, Nakashima H, Tanaka A, Maehara T, et al. Interleukin-33 produced by M2 macrophages and other immune cells contributes to Th2 immune reaction of IgG4related disease. Sci Rep 2017;7:42413.

43. Watanabe T, Yamashita K, Fujikawa S, Sakurai T, Kudo M, Shiokawa $\mathrm{M}$, et al. Involvement of activation of toll-like receptors and nucleotide-binding oligomerization domain-like receptors in enhanced IgG4 responses in autoimmune pancreatitis. Arthritis Rheum 2012;64:914-24.

44. Watanabe T, Yamashita K, Sakurai T, Kudo M, Shiokawa M, Uza $\mathrm{N}$, et al. Toll-like receptor activation in basophils contributes to the development of IgG4-related disease. J Gastroenterol 2013;48:24753.

45. Ishiguro N, Moriyama M, Furusho K, Furukawa S, Shibata T, Murakami Y, et al. Activated M2 macrophages contribute to the pathogenesis of IgG4-related disease via toll-like receptor 7/interleukin-33 signaling. Arthritis Rheumatol 2020;72:166-78.

46. Kamisawa T, Shimosegawa T, Okazaki K, Nishino T, Watanabe H, Kanno A, et al. Standard steroid treatment for autoimmune pancreatitis. Gut 2009;58:1504-7.

47. Masaki Y, Matsui S, Saeki T, Tsuboi H, Hirata S, Izumi Y, et al. A multicenter phase II prospective clinical trial of glucocorticoid for patients with untreated IgG4-related disease. Mod Rheumatol 2017;27:849-54.

48. Hong X, Zhang YY, Li W, Liu YY, Wang Z, Chen Y, et al. Treatment of immunoglobulin G4-related sialadenitis: outcomes of glucocorticoid therapy combined with steroid-sparing agents. Arthritis Res Ther 2018;20:12.

49. Masamune A, Nishimori I, Kikuta K, Tsuji I, Mizuno N, Iiyama T, et al. Randomised controlled trial of long-term maintenance corticosteroid therapy in patients with autoimmune pancreatitis. Gut 2017;66:487-94.

50. Shimosegawa T, Chari ST, Frulloni L, Kamisawa T, Kawa S, MinoKenudson M, et al. International consensus diagnostic criteria for autoimmune pancreatitis: guidelines of the International Association of Pancreatology. Pancreas 2011;40:352-8.

51. Moriyama M, Tanaka A, Maehara T, Ohyama Y, Shimizu M, Nakashima H, et al. Clinical characteristics of Mikulicz's disease as an IgG4-related disease. Clin Oral Investig 2013;17:1995-2002.

52. Maehara T, Mattoo H, Mahajan VS, Murphy SJ, Yuen GJ, Ishiguro $\mathrm{N}$, et al. The expansion in lymphoid organs of IL- $4^{+} \mathrm{BATF}^{+} \mathrm{T}$ follicular helper cells is linked to IgG4 class switching in vivo. Life Sci Alliance 2018;1:e201800050.

53. Wallace ZS, Deshpande V, Stone JH. Ophthalmic manifestations of IgG4-related disease: single-center experience and literature review. Semin Arthritis Rheum 2014;43:806-17.

54. Baer AN, Gourin CG, Westra WH, Cox DP, Greenspan JS, Daniels $\mathrm{TE}$, et al. Rare diagnosis of IgG4-related systemic disease by lip biopsy in an international Sjögren syndrome registry. Oral Surg Oral Med Oral Pathol Oral Radiol 2013;115:e34-9.

55. Yamamoto M, Takahashi H, Sugai S, Imai K. Clinical and pathological characteristics of Mikulicz's disease (IgG4-related plasmacytic exocrinopathy). Autoimmun Rev 2005;4:195-200.

56. Hu EK, Parrish C, Wrobel B, Deshpande V, Stone JH. Immunoglobulin G4-related disease presenting as an ethmoid and maxillary mass. Ann Allergy Asthma Immunol 2013;111:75-7.

57. Dahlgren M, Khosroshahi A, Nielsen GP, Deshpande V, Stone JH. Riedel's thyroiditis and multifocal fibrosclerosis are part of the IgG4-related systemic disease spectrum. Arthritis Care Res (Hoboken) 2010;62:1312-8.

58. Cheuk W, Chan JK. Lymphadenopathy of IgG4-related disease: an underdiagnosed and overdiagnosed entity. Semin Diagn Pathol 2012;29:226-34.

59. Stone JH, Zen Y, Deshpande V. IgG4-related disease. N Engl J Med 2012;366:539-51.

60. Khosroshahi A, Carruthers MN, Stone JH, Shinagare S, Sainani N, Hasserjian RP, et al. Rethinking Ormond's disease: "idiopathic" retroperitoneal fibrosis in the era of IgG4-related disease. Medicine (Baltimore) 2013;92:82-91.

61. Inoue D, Zen Y, Abo H, Gabata T, Demachi H, Kobayashi T, et al. Immunoglobulin G4-related lung disease: CT findings with pathologic correlations. Radiology 2009;251:260-70.

62. Saeki T, Nishi S, Imai N, Ito T, Yamazaki H, Kawano M, et al. Clinicopathological characteristics of patients with IgG4-related tubulointerstitial nephritis. Kidney Int 2010;78:1016-23.

63. Stone JH, Khosroshahi A, Deshpande V, Chan JK, Heathcote JG, Aalberse R, et al. Recommendations for the nomenclature of IgG4related disease and its individual organ system manifestations. Arthritis Rheum 2012;64:3061-7.

64. Zen Y, Harada K, Sasaki M, Sato Y, Tsuneyama K, Haratake J, et al. IgG4-related sclerosing cholangitis with and without hepatic inflammatory pseudotumor, and sclerosing pancreatitis-associated 
sclerosing cholangitis: do they belong to a spectrum of sclerosing pancreatitis? Am J Surg Pathol 2004;28:1193-203.

65. Mattoo H, Della-Torre E, Mahajan VS, Stone JH, Pillai S. Circulating Th2 memory cells in IgG4-related disease are restricted to a defined subset of subjects with atopy. Allergy 2014;69:399-402.

66. Maehara T, Moriyama M, Nakashima H, Miyake K, Hayashida $\mathrm{JN}$, Tanaka A, et al. Interleukin-21 contributes to germinal centre formation and immunoglobulin G4 production in IgG4-related dacryoadenitis and sialoadenitis, so-called Mikulicz's disease. Ann Rheum Dis 2012;71:2011-9.

67. Akiyama M, Suzuki K, Yasuoka H, Kaneko Y, Yamaoka K, Takeuchi T. Follicular helper T cells in the pathogenesis of IgG4-related disease. Rheumatology (Oxford) 2018;57:236-45.

68. Kamekura R, Takano K, Yamamoto M, Kawata K, Shigehara K, Jitsukawa $\mathrm{S}$, et al. Cutting edge: a critical role of lesional $\mathrm{T}$ follicular helper cells in the pathogenesis of IgG4-related disease. J Immunol 2017;199:2624-9.

69. Kamekura R, Yamamoto M, Takano K, Yabe H, Ito F, Ikegami I, et al. Circulating PD- $1^{+} \mathrm{CXCR} 5 \mathrm{CD}^{+} \mathrm{T}$ cells underlying the immunological mechanisms of IgG4-related disease. Rheumatol Adv Pract 2018;2:rky043.

70. Perugino CA, AlSalem SB, Mattoo H, Della-Torre E, Mahajan $\mathrm{V}$, Ganesh G, et al. Identification of galectin-3 as an autoantigen in patients with $\mathrm{IgG}_{4}$-related disease. J Allergy Clin Immunol 2019;143:736-45.e6.

71. Shiokawa M, Kodama Y, Kuriyama K, Yoshimura K, Tomono T,
Morita T, et al. Pathogenicity of IgG in patients with IgG4-related disease. Gut 2016;65:1322-32.

72. Furukawa S, Moriyama M, Tanaka A, Maehara T, Tsuboi H, Iizuka M, et al. Preferential M2 macrophages contribute to fibrosis in IgG4-related dacryoadenitis and sialoadenitis, so-called Mikulicz's disease. Clin Immunol 2015;156:9-18.

73. Ohta M, Moriyama M, Maehara T, Gion Y, Furukawa S, Tanaka A, et al. DNA microarray analysis of submandibular glands in IgG4-related disease indicates a role for MARCO and other innate Immune-related proteins. Medicine (Baltimore) 2016;95:e2853.

74. Perugino CA, Stone JH. Treatment of IgG4-related disease: current and future approaches. Z Rheumatol 2016;75:681-6.

75. Perugino CA, Mattoo H, Mahajan VS, Maehara T, Wallace ZS, Pillai $\mathrm{S}$, et al. Emerging treatment models in rheumatology: IgG4related disease: insights into human immunology and targeted therapies. Arthritis Rheumatol 2017;69:1722-32.

How to cite this article: Maehara T, Moriyama M, Nakamura S. Review of a novel disease entity, immunoglobulin G4-related disease. J Korean Assoc Oral Maxillofac Surg 2020;46:3-11. https:// doi.org/10.5125/jkaoms.2020.46.1.3 